\title{
UN SUPUESTO DE INAPLICABILIDAD DEL ARTÍCULO 1762 DEL CÓDIGO CIVIL EN MATERIA DE RESPONSABILIDAD MÉDICA: APUNTES PARA UN NUEVO ENFOQUE DE LA RESPONSABILIDAD CIVIL DE LOS PROFESIONALES.
}

\author{
NinAMANCCO CÓRDOVA, Fort *
}

\begin{abstract}
SUMARIO: 1. Introducción. - 2. Las críticas al artículo 1762 del Código civil. - 3. Las interpretaciones propuestas y sus inconvenientes. -4 . Los defensores del artículo 1762 del CC. Y los nuevos argumentos para la defensa del privilegio en el campo de la responsabilidad civil médica. - 5. Una cuestión en la penumbra: ¿el art. 36 de la Ley General de Salud impide la aplicación del art. 1762 del CC en la actividad médica?. - 6. Desaplicando el art. 1762 del CC: el caso del art. 3.5 de la Ley de Personas Adultas Mayores. - 7. Otras posibilidades de desaplicación.
\end{abstract}

\section{Introducción}

Cuestiones no poco problemáticas se encuentran encerradas en la temática de la responsabilidad civil de los profesionales. Tan es así que la idea misma de responsabilidad profesional, como tipo especial de responsabilidad civil, ha sido cuestionada duramente por un autorizado sector de la doctrina. En este sentido, se afirma sin vacilar que "la responsabilidad profesional no existe ${ }^{, 84}$. No obstante, nadie niega que, para bien o para mal, nuestro Código Civil asume que la responsabilidad profesional merece un tratamiento diferenciado al resto de supuestos de responsabilidad civil. Esto se comprende fácilmente al leer el artículo 1762 de este código, el cual consagra un régimen de responsabilidad diferente para los profesionales.

A esta diferenciación ha sido el blanco de enérgicas críticas por parte de un amplio sector de nuestros autores más reputados, realizándose esfuerzos interpretativos importantes orientados a la reducción máxima del radio de acción de este régimen especial. Pero, como veremos, no han faltado autorizados defensores de tal régimen.

De hecho, ocurre que los propios críticos de la norma no están del todo de acuerdo con respecto a los alcances que se le deben dar. Incluso, dada la redacción del artículo citado, se ha dudado de la posibilidad de lograr una interpretación satisfactoria para los intereses de la víctima del daño. En un escenario como este, la corriente de opinión que no reniega, sino que acepta, la diferenciación tiene las de ganar en plano operativo. Y efectivamente así ha sido, basta observar algunos pronunciamientos judiciales para caer en la cuenta de que

\footnotetext{
* Abogado por la Universidad Nacional Mayor de San Marcos. Egresado de la Maestría en Derecho de la misma casa de estudios. Profesor de Derecho Civil en las universidades de San Martín de Porres, Inca Garcilaso de la Vega, Ricardo Palma y San Juan Bautista.

84 DE TRAZEGniES GRANDA, Fernando La responsabilidad profesional no existe. En: AAVV. Instituciones de Derecho Privado. Vol. 5. Responsabilidad civil. Derecho de daños. Dirigido por José Luis DE Los Mozos y Carlos Soto CoAGuILA. Lima: Grijley, 2006, p. 359: (...) lo que no creo es que exista una institución o figura jurídica independiente, que pueda llamarse responsabilidad profesional.
} 
nuestros jueces interpretan literalmente el artículo 1762 del Código Civil, resaltando y aplicando el privilegio en el que se traduce el régimen de responsabilidad profesional que establece este cuerpo normativo.

Debe decirse, entonces, que para quienes consideramos que resulta discutible que los profesionales -incluidos nosotros, los abogados - tengan un privilegio por el mero hecho de ser tales, es necesario abordar este asunto bajo un enfoque diferente ¿Cómo? Pues indagando la posibilidad de identificar supuestos donde el privilegio criticado no pueda ser aplicado de conformidad con la normatividad vigente, incluso bajo una interpretación literal de la misma. Nótese bien, no se trata de desaplicar el artículo 1762 del Código Civil a ciertos supuestos en base a una interpretación restrictiva, sino de verificar la existencia de supuestos especiales que, dada su regulación, excluyen la aplicación de esta norma civil.

Interpretar de una manera "saludable" el precepto en cuestión no es objeto de estas líneas. Y a decir verdad, sin embargo, trabajar en efectuar tal interpretación parece ya una tarea no muy necesaria, porque en nuestra doctrina ya se ha hecho con cierta amplitud, y los resultados - como ya se indicó- no han sido alentadores. Pero se hará referencia a las interpretaciones que se han ensayado en torno al artículo 1762 del Código Civil, aunque si bien no se tomará partido expresamente por una de ellas, sí se efectuaran algunas anotaciones críticas sobre aspectos que considero neurálgicos. Tal referencia es inevitable toda vez que es obvio que no se puede prescindir de un marco de referencia básico de la norma cuya desaplicación se busca.

Estos apuntes, en consecuencia, tienen un objetivo más modesto: llamar la atención sobre algunos aspectos descuidados en el debate existente en torno el privilegio otorgado a los profesionales en el ámbito de la responsabilidad civil, para lo cual también se esbozarán algunos planteamientos que permitan sostener que el mentado artículo, al margen de la interpretación que se le dé, no se aplica a los pacientes adultos mayores. Con esto espero contribuir, al menos con un granito de arena, a que se tenga una visión más integral de la responsabilidad civil de los profesionales.

\section{Las críticas al artículo 1762 del Código Civil}

Más de una dura crítica ha recibido el artículo 1762 de nuestro Código Civil. Por un lado se le ha catalogado de anacrónico, ya que el privilegio que esta norma otorga a los profesionales sólo encontraría alguna justificación en un contexto social que considera al profesional como portador de un estatus especial dentro de la comunidad, dados sus especiales conocimientos que le otorgarían una especie de "autoridad cultural"85. Al respecto, un sector de la doctrina italiana enseña que el privilegio de los profesionales en materia de responsabilidad civil (téngase presente que el legislador peruano, para establecer el artículo 1762 del Código Civil, se inspiró en el artículo 2236 del Código Civil italiano) se basa en la retórica de la "misión social", que concibe a la actividad profesional no sólo como socialmente relevante, sino también como carente de afán de lucro. Esta visión, que tomaría como paradigma al médico y al abogado, entiende que la actividad profesional tendría como rasgos distintivos la dependencia, la dignidad y el desinterés, lo que justificaría colocar al profesional por encima de los riesgos que implica la eventual producción de daños al cliente, limitando su responsabilidad civil ${ }^{86}$.

\footnotetext{
${ }^{85}$ Woolcott OYAGUe, Olenka, La responsabilidad civil de los profesionales. Lima, Ara, 2002, p. 149.

${ }^{86}$ FoRTINO, Marcela, La responsabilità civile del profesionista. Milán, Giuffrè, 1984, pp. 35-40.
} 
Esta perspectiva ha sido rebasada por la realidad hace mucho tiempo. En este sentido, según explica una autorizada doctrina nacional ${ }^{87}$, hoy en día carece de sentido pretender trazar una línea clara entre actividades profesionales y no profesionales, de modo que aquéllas sean más importantes que éstas y, por ende, merezcan un privilegio normativo en el ámbito de su responsabilidad. Por el contrario, según esta doctrina, hoy en día vivimos en la época del profesionalismo, ya no sabemos lo que es exactamente un profesional: nunca ha habido tantos profesionales como ahora y, sin embargo, la búsqueda - desde el punto de vista conceptual- de un profesional puede ser tan penosa como la de Diógenes con su lámpara cuando trataba de encontrar un hombre. (...) Si alguna vez supimos lo que era un profesional, ciertamente parece que lo hubiéramos olvidado; y, cuando nos aproximamos con más detalle a ese mundo que llamamos profesional, advertimos que se encuentra poblado por múltiples ejemplares de especies diferentes, que difícilmente se acomodan bajo un mismo género. (...) Este tema es muy importante porque, sin profesionales, nos quedamos sin responsabilidad profesional: si no podemos distinguir nítidamente una especie aparte de hombre que practican una variedad independiente de actividades que llamamos profesional, tampoco podremos diferenciar la responsabilidad civil común y corriente de una llamada responsabilidad profesional.

Girando el análisis hacia la posición del tomador del servicio profesional, se advierte que existe una evidente disparidad entre el profano y el profesional con respecto al asunto materia de la relación jurídica que se entabla entre ambos, lo cual explica que si alguien acude a un profesional, hace una especial manifestación de confianza. Tomar el servicio profesional implica confiar los propios intereses en la actividad incontrolada e incontrolable del profesional, ya que la disparidad aludida priva al interesado de cualquier control real sobre tal actividad. Entonces, dicha confianza se ve traicionada por la normativa cuando ésta no exige al profesional una mayor diligencia en sus actuaciones, sino que, por el contrario, le confiere un privilegio que le permite no asumir ninguna responsabilidad por no emplear la diligencia ordinaria al desempeñar sus actividades ${ }^{88}$.

Un concepto unitario de culpa también ha servido de fundamento para las críticas: no tiene sentido establecer una "culpa profesional" diferente a otras culpas. A groso modo puede decirse que la culpa suele ser asociada a la idea de actuación carente de diligencia, de modo que un comportamiento es culposo cuando no se emplean, de modo adecuado, las energías y los medios útiles para la realización de un fin determinado ${ }^{89}$. Si aplicamos esta noción a la conducta profesional, obtendremos la llamada "culpa profesional", la que podría entenderse como falta de "diligencia profesional". Entonces, cabe preguntar si hay una razón de peso para considerar que se trata de una diligencia diversa a la común. La respuesta es negativa, ya que no debe olvidarse que la diligencia- y por ende la culpa- es un concepto flexible, que se adapta a las circunstancia de cada caso. No existe, pues, ninguna clase de inconveniente para aplicar la noción común de diligencia a las actividades profesionales: según los diversos fines, el esfuerzo que es identificable con la diligencia puede exigir la aplicación de facultades volitivas, el recurso a instrumentos materiales idóneos, la observancia de principios técnicos y de preceptos jurídicos ${ }^{90}$.

\footnotetext{
${ }^{87}$ De TraZEGNIES GRANDA, Fernando, Op. cit. pp. 373-374.

${ }^{88}$ ForTINO, Marcela, Op. cit. p. 101.

89 BIANCA, Massimo, La negligencia en el derecho civil italiano. En: AAVV. Estudios sobre la responsabilidad civil. Traducción y edición de Leysser LEÓN. Lima: Ara, 2001, pp. 345 y 346.

${ }^{90}$ Ibid. p. 346.
} 
Sobre la base de esta idea, se asevera que en realidad la "diligencia profesional" es la diligencia común que es debida en un acto profesional, cuyo defecto nos coloca en el plano de la llamada también "culpa profesional". No hay pues una culpa profesional propiamente dicha; del mismo modo, la diligencia exigible será la reclamada por la naturaleza del acto profesional que ha de ejecutarse, las circunstancias de las personas, del tiempo y del lugar ${ }^{91}$. Consecuentemente, resulta contradictorio que se establezca una atenuación de la responsabilidad de los profesionales, ya que un elemental criterio de justicia exige que el nivel de diligencia de los profesionales se encuentre en función al grado de dificultad de los problemas afrontados ${ }^{92}$. Bajo esta línea de pensamiento, se justifica plenamente la afirmación según la cual el artículo 1762 del Código Civil establece una protección exagerada para el profesional $^{93}$.

También se advierte que el carácter desinteresado prácticamente ha desaparecido del ámbito de la responsabilidad profesional, de modo que hoy en día ésta se caracteriza por desarrollarse dentro de un marco comercial a cargo de una empresa. Es más, por lo general los profesionales no ejercen de forma independiente: abogados, médicos e ingenieros, por citar sólo tres ejemplos emblemáticos, trabajan para empresas comerciales e industriales; o se asocian en genuinas empresas comerciales que conforman clínicas, empresas de consultoría y bufetes de abogados. En un contexto como este, es harto difícil hablar de un profesional liberal. La idea de independencia de los profesionales, que es otro presupuesto de la noción clásica de la actividad profesional, es hoy casi una excepción ${ }^{94}$.

Adviértase que los críticos precisan que no se pretende negar o cuestionar la importancia de la actividad profesional ni muchos menos su dignidad. De lo que se trata es de manejar una visión de la actividad profesional que sea conforme a la realidad actual, no en función de consideraciones socialmente irreales ${ }^{95}$. En tal sentido, se trata, pues, de tomar conciencia de que las nuevas modalidades en que se desarrollan las actividades profesionales y el surgimiento de nuevas especializaciones o profesiones, alteran de manera radical los viejos marcos de referencia que tuvo en cuenta el legislador al momento de establecer el privilegio criticado ${ }^{96}$.
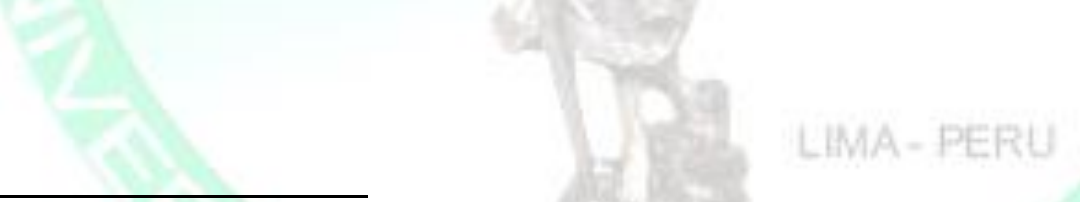

${ }^{91}$ WoOlCOTt OYague, Olenka, Op. cit. p. 523.

${ }^{92}$ Mario ZANA. Responsabilità del profesionista. En: AAVV. Enciclopedia Giuridica. Vol. XXVI. Roma: Istituto della Enciclopedia Italiana, 1991, p. 7.

${ }^{93}$ FERNÁNDEZ CRUZ, Gastón, Responsabilidad civil médica. En: Diálogo con la jurisprudencia. Año I. $\mathrm{N}^{\circ}$ 1. Lima: Gaceta Jurídica, 1995, p. 62: (...) Sin embargo, es el artículo $1762^{\circ}$ del C.C., dentro de las disposiciones generales de la prestación de servicios, el que regula la prestación de servicios profesionales, entre ellos, la prestación de servicios médicos, en donde, bajo un claro matiz proteccionista "in extremis" de los servicios profesionales se indica que "... si la prestación de servicios implica la solución de asuntos profesionales o de problemas técnicos de especial dificultad, el prestador de servicios no responde por los daños y perjuicios, sino en caso de dolo o culpa inexcusable" (el resaltado es agregado).

${ }^{94}$ Fernando De TraZeGnies GrandA. Op. cit. p. 379 y Olenka WoOlCOTT OYague. Op. cit. pp. 150 y 151.

${ }^{95}$ WoOlCOtt OYague, Olenka, Op. cit. p. 151.

${ }^{96}$ FortinO, Marcela, Op. cit. p. 40. De TrAZEGNIES GRANDA, Fernando Op. cit. p. 380: El problema está en que en el mundo de hoy, es verdaderamente muy raro encontrar una prestación de servicios que no exija alguna calificación. En consecuencia cada vez sabemos menos lo que son las actividades profesionales que exigen una especialidad, porque prácticamente todos los oficios y trabajos requieren hoy en día poner en juego la inteligencia y la experiencia en mayor o menor grado, al punto que casi toda actividad se vuelve de alguna manera especializada. 


\section{Las interpretaciones propuestas y sus inconvenientes}

Resaltar los aspectos criticables de una norma no es suficiente. Por eso la doctrina crítica del privilegio no se ha contentado con resaltar la debilidad de su fundamento, sino que también ha propuesto algunas interpretaciones que buscan paliar de algún modo los efectos negativos que tendría la norma contenida en el artículo 1762 del Código Civil. Veamos:

Interpretaciones de tipo restrictivo, como no podía ser de otra manera, han sido esbozadas para la regulación contenida en el artículo 1762 del Código Civil. Así, sobre la base de los postulados de una atenta doctrina italiana ${ }^{97}$, parte de nuestra doctrina afirma que debe entenderse que el privilegio se refiere sólo a la pericia, no a la diligencia, de tal manera que sólo cuando el cumplimiento de la obligación implique un significativo grado de dificultad, será procedente aplicar el artículo 1762 del Código Civil. Se entiende que a la pericia como el aspecto técnico de la diligencia. Empero, si no media tal dificultad, el profesional se encontrará sometido al régimen general de responsabilidad civil. Es más, debe considerarse que si el profesional asume libremente una obligación cuya prestación resulta ser exorbitante frente a sus capacidades, no puede oponer el privilegio al eventual damnificado ${ }^{98}$.

Un destacado autor, años antes, ya se había pronunciado en sentido análogo: la limitación de la responsabilidad profesional y especialmente médica, sólo será posible de invocarse en casos en donde el estado actual del conocimiento científico no permita afirmar nada cierto en torno a una enfermedad o acto médico, por no existir experiencia al respecto $^{99}$. Fuera de este ámbito, el profesional deberá responder conforme al régimen general de responsabilidad, siendo suficiente la presencia de culpa leve para asignar responsabilidad civil. Empero, se precisa que en casos en los que el avance de la ciencia médica ha logrado dominar por completo una enfermedad o técnica de curación, el médico tendrá que asumir una responsabilidad objetiva. Así ocurriría, por ejemplo, en una intervención quirúrgica necesaria para neutralizar una amigdalitis o una apendicitis ${ }^{100}$.

Contra las soluciones propuestas hay más de un obstáculo que han sido advertidos por los propios críticos. Nótese, pues, que los inconvenientes de la aplicación de la interpretación restrictiva no han sido constados, como podría esperarse, por los defensores de la norma en cuestión. De este modo, se lamenta que tal como se halla redactada la norma y considerando desafortunadamente el nivel de nuestra jurisprudencia, la solución que haya que adoptarse, seguramente será favorable para el prestador del servicio profesional, dejándose de lado todo elemento de juicio que implique un esfuerzo en el razonamiento jurídico, lo que

97 ZANA, Mario, Op. cit. pp. 5 y 6, quien informa que la jurisprudencia italiana ha recogido ampliamente esta perspectiva al enfrentar problemas de aplicación del artículo 2236 de su código civil.

${ }^{98}$ WoOlCotT OYague, Olenka, Op. cit. pp. 528 y 529. No obstante, debo indicar que resulta no poco discutible que si el profesional asume "una prestación exorbitante a sus posibilidades", nos encontremos ante verdadero un contrato de efectos obligatorios. Un deber (como la obligación) cuyo cumplimiento escapa a la esfera de control del gravado con el mismo, no es un deber en sentido técnico (tal como lo advierte un excelso autor: BetTI, Emilio, Dovere giuridico. En: AAVv. Enciclopedia del Diritto. T. XIV. Milán: Giuffrè, 1965, p. 57), por lo que podría decirse que el profesional, más que asumir una obligación, asume un riesgo. El efecto no sería, pues, obligatorio, sino, como suele decirse, de "garantía", tal como ocurre en el contrato de promesa de la obligación o del hecho de un tercero (sobre el particular: Hugo FORNO FLOREZ. Precisiones conceptuales en torno a la promesa de hecho ajeno. En: AAVV. Negocio jurídico y responsabilidad civil. Estudios en memoria de Lizardo Taboada Córdova. Lima: Grijley, 2004, pp. 535 y ss.).

${ }^{99}$ FERNÁNDEZ CRUZ,. Gastón, Op. cit. p. 63.

${ }^{100}$ Ibid. p. 64. 
ciertamente es lamentable $^{101}$. Se agrega que la redacción de la norma es, a fin de cuentas, poco clara, de modo que puede pensarse que el artículo 1762 del Código Civil puede referirse a todos los daños en asuntos profesionales y en los problemas técnicos sólo cuando estos involucren especial dificultad (...), de modo que sostener otra interpretación, como la restrictiva ya reseñada que entiende que la calificación de "especial dificultad" se aplica tanto a las actividades profesionales como a las técnicas, resulta reiterativa y, por ende, contraria a la buena técnica de interpretación jurídica: es mala técnica legislativa usar sinónimos y reiteraciones porque no aclaran sino que confunden. $Y$ como debemos suponer que los códigos están bien hechos y que no están mal hechos, tenemos que concluir que se trata de dos hipótesis distintas, la profesional y la técnica ${ }^{102}$. Por tanto, según esta consideración, la interpretación que considera que el privilegio sólo se aplica a los asuntos profesionales especialmente difícil, incurriría en error interpretativo al presuponer una redundancia. En este mismo sentido, con respecto al artículo 2236 del Código Civil italiano, se dice-con "aire" pesimista- que es una norma que, para bien o para mal, hemos hecho nuestra ${ }^{103}$.

\section{Los defensores del artículo 1762 del Código Civil y dos nuevos argumentos para la defensa del privilegio en el campo de la responsabilidad civil médica}

Ocurre, sin embargo, que los críticos no sólo deben enfrentar la poco favorable redacción de la normativa objeto de sus objeciones, sino también los interesantes argumentos que se pueden construir en base a los planteamientos de los defensores de tal normativa.

No es correcto pensar que el legislador peruano, a semejanza de su homólogo italiano, tuvo en mente aquel viejo marco social justificador de privilegios legales para los profesionales. Otras motivaciones, muy distintas, habrían estado detrás de la consagración del artículo 1762 del Código Civil: incentivar la innovación y el desarrollo en las actividades profesionales, para bienestar de nuestra sociedad ${ }^{104}$.

Otras consideraciones, sin embargo, también han sido esgrimidas en defensa de la normativa tantas veces aludida. Así, una reputada doctrina afirma que con tal normativa se busca evitar la multiplicación de procesos judiciales y se excluye la culpa leve, con lo cual desaparecerá el peligro de que se les haga imputables por toda clase de errores y no se produzca, como reacción, una actitud de negativa y abstención de servicios que son indispensables a niveles profesionales y técnicos ${ }^{105}$. Empero, se admite que esta norma peruana es posiblemente discutible, pero no aberrante ${ }^{106}$. Como es de esperar, el autor que ahora cito no sostiene una interpretación restrictiva, sino que asevera que el privilegio se aplica a todo asunto profesional, de modo que la "especial dificultad" hace referencia solamente a problemas técnicos. Se entiende que habrá culpa inexcusable cuando se falte a las reglas fundamentales de la ciencia, arte u oficio ${ }^{107}$.

${ }^{101}$ WoolcotT Oyague,. Olenka, Op. cit. p. 538.

${ }^{102}$ De TraZeGnies GrandA, Fernando Op. cit. p. 388.

103 LEÓN HILARIO, Leysser. Apuntes sobre la prueba de la responsabilidad civil del médico dependiente de un centro de salud. En: ID. La responsabilidad civil. Lineamientos fundamentales y nuevas perspectivas. Lima: Jurista, 2007, p. 793.

${ }^{104}$ Arias SchreIBER PeZET, Max, Exégesis. T. III. Lima: Studium, 1987, pp. 86 y 87.

105 Ibid. p. 86.

106 Loc. cit.

${ }^{107}$ Ibid. p. 87. 
Consideraciones semejantes han sido esgrimidas por otro eximio autor: la ratio legis de la norma era la de no mortificar la iniciativa profesional con el temor de injustas represalias de parte del cliente y no inducir a decisiones no ponderadas, ni a inercias reprobables por parte del profesional ${ }^{108}$. Luego le pone el acento en la idea de innovación, señalándose, por un lado, que el continuo avance de la ciencia en todas las ramas de la actividad humana hace que constantemente surjan nuevos métodos para resolver problemas técnicos o científicos, pero cuya eficacia no ha sido del todo comprobada. Por otro lado, suele ocurrir que problemas de fácil solución, cobran inusitada dificultad. Este par de circunstancias hace necesario experimentar nuevas soluciones (...) de manera que si se aplica el régimen general de la responsabilidad civil existiría un fundado temor de incurrir en responsabilidad por aplicar nuevas técnicas que no han tenido una aplicación generalizada, especialmente si se trata de ciencias no exactas ${ }^{109}$.

Es comprensible que el legislador sacrifique la exigencia de una diligencia ordinaria en aras de lograr el avance de la ciencia, tanto más cuanto que el comitente de los servicios conoce la especial dificultad del problema. La observancia de la diligencia ordinaria bien puede acarrear que el prestador de servicios se abstenga de incursionar en campos aún no bien explorados, sacrificando en lo posible el beneficio para el comitente. Esto sería así porque la observancia de la diligencia ordinaria ocasionaría que el profesional se ciña a las soluciones ya conocidas, descartando-por temor fundado- soluciones novedosas pero que ofrecen un menor índice de seguridad o confiabilidad ${ }^{110}$.

Repárese en que esta doctrina auspicia una interpretación restrictiva: no se plantea que el prestador de servicios sea exonerado en todos los casos de responsabilidad por culpa leve sino únicamente cuando la inejecución de la obligación es por razón de la especial dificultad de los problemas técnicos (...) lo importante es que los problemas sean científicos o técnicos y tengan especial dificultad, la cual debe ser conocida por las partes. En ese sentido, se concluye que es comprensible la dificultad de optar entre la posición de exigir al prestador de servicios la observancia de la diligencia ordinaria y la de propiciar el avance de la ciencia y de la técnica, aun a costa de una irresponsabilidad del deudor, pero en la necesidad de hacerlo opto por la segunda posición ${ }^{111}$.

Tiene que decirse que, a la luz de lo expuesto hasta aquí, pueden surgir múltiples cuestiones que no serán analizadas en esta sede ${ }^{12}$. Me interesa, más bien, esbozar algunas consideraciones adicionales a favor del privilegio, sobre todo en el ámbito médico, tomando como base lo dicho por los dos connotados autores que se acaban de citar.

108 De la Puente y Lavalle, Manuel. El artículo 1762 del Código Civil peruano. En: AaVv. Instituciones de Derecho Privado. Vol. 5. Responsabilidad civil. Derecho de daños. Cit. p. 35 (en donde se precisa que esta explicación corresponde también a la "exposición de motivos" del artículo 2236 del Código Civil italiano, redactada por el ministro Dino GRANDI).

\footnotetext{
${ }^{109}$ Loc. cit.

${ }^{110}$ Ibid. p. 37.

111 Ibid. p. 38.
}

${ }^{112}$ Habrá advertido un lector atento, por ejemplo, que la propuesta interpretativa de Manuel DE LA PUENTE podría considerarse contraria a la jurisprudencia dominante en Italia. Mientras ésta, como ya se vio según la información que nos proporciona Mario ZANA, indica que el profesional pierde el privilegio si asume conscientemente una "obligación que excede sus posibilidades". Pero, según la lectura del maestro peruano, el privilegio se mantiene en estos casos, al afirmar que la "especial dificultad" debe ser conocida por las partes. 
En primer lugar se podrían alegar argumentos de carácter económico social para el mantenimiento del privilegio. Directo al grano: países como el Perú necesitan repotenciar sus actividades científicas con suma urgencia, y en esta tarea sería de suma utilidad otorgar el privilegio a los profesionales, cuando éstos se enfrenten a problemas de especial dificultad. Para sustentar esta idea podríamos echar mano a los muy sugerentes planteamientos de un destacado analista político internacional: los países latinoamericanos están condenados al permanente retraso y dependencia de las potencias, si no toman medidas efectivas para alcanzar un desarrollo propio en las diferentes disciplinas científicas. En este sentido, el reputado analista advierte que cada país debe repotenciar sus recursos tecnológicos, atendiendo a las necesidades de mercado que lo rodean ${ }^{113}$. Si bien ciertos planteamientos de este autor no los comparto, como el lugar que otorga a las ciencias sociales en su discurso, es interesante llamar la atención sobre este planteamiento, que puede servir para defender la idea de que el privilegio de los profesionales a nivel de responsabilidad civil es necesario, ya que con él se facilita la innovación científica (tal como afirman los defensores del artículo 1762 del Código Civil), la cual tiene una importancia decisiva en el futuro económico del país entero. Creo que es algo que no necesita demostración la gran importancia que el desarrollo de la medicina tiene en el desarrollo económico social de un país, por lo que una regulación como la contenida en el citado artículo de nuestro código civil puede ser patrocinada por aquellos postulados que se preocupan y tienen en cuenta el rol de la innovación y desarrollo en el campo de las ciencias, y la necesidad de incentivarlos.

Asimismo, y en segundo lugar, es posible desarrollar argumentos que inclusive establezcan el privilegio para los médicos no sólo en asuntos de especial dificultad, sino de manera general, esto es en todo asunto de su profesión. En efecto, si se considera que los jueces peruanos tienden a ser excesivamente exigentes con los médicos al momento de valorar su culpa, pues sí tendría justificación la necesidad de mantener el privilegio. Éste tendría como función, claro está, disminuir la posibilidad de que los médico asuman responsabilidad civil por cualquier tipo de inconveniente que se pudiera presentar con el paciente, pese a que el mismo pudo estar fuera de su razonable control. Aquí cabe recordar un caso emblemático que es analizado por un importante sector de nuestra doctrina ${ }^{114}$ :

No obstante que existen varios elementos técnicos que no pueden ser precisados en este lugar, del caso aludido resulta que los jueces consideran que un médico incurre en culpa inexcusable cuando omite realizar un examen para detectar una fistula que podría complicar una intervención quirúrgica, pero cuya posibilidad de presencia era del $0.03 \%$ ¿Realmente hay culpa inexcusable cuando un médico omite realizar un examen para evadir un riesgo de complicación quirúrgica que no supera las cinco (05) centésimas porcentuales? Pues según la Resolución $\mathrm{N}^{\circ} 149$ del 25.07.2003 expedida por el $28^{\circ}$ Juzgado especializado en lo Civil de la Corte Superior de Lima, la respuesta es positiva:

Indica el Juez que el médico tratante y el asistente omitieron realizar los exámenes necesarios para diagnosticar un granuloma, una tumoración rectal, la fibrosis, el debilitamiento de tejidos o fístula (...) según el tratado Campbell's Urology (...) las fístulas enterovesicales no son desconocidas, se presentan en una de cada 3000 intervenciones quirúrgicas y son detectables clínicamente, tanto radiológica como endoscópicamente; a pesar de que ninguno de los exámenes por sí solo es exacto, una combinación de procedimientos permite el diagnóstico de las fístulas enterovesicales, su origen, así como su

113 OpPenHeIMER, Andrés, Cuentos chinos. Buenos Aires: Sudamericana, 2005, pp. 17 y ss.; 89 y ss.; y 321 y ss.

${ }^{114}$ EsPINOZA EsPINOZA, Juan Derecho de la responsabilidad civil. Lima: Rodhas, 2011, pp. 732-735. 
causa subyacente en la mayoría de los casos. Pero como los médico demandados no acreditaron haber realizados los exámenes para detectar esta fístula, el juez concluye que está demostrado que el médico tratante y el médico asistente actuaron de manera culpable e inexcusable. Esta idea fue confirmada por la $1^{\circ}$ Sala Civil de la Corte Superior de Justicia de Lima y la Sala Civil permanente de la Corte Suprema de Justicia de la República mediante resolución del 14.11.2005 (Cas. $\mathrm{N}^{\circ}$ 549-2005).

Me parece que se pueden proponer serias objeciones contra esta decisión. No sólo se trata de que evadir una contingencia del $0.03 \%$ de probabilidad de ocurrencia (la fístula que ocasionó la complicación tenía una probabilidad de ocurrencia en extremo baja, al presentarse en solo uno de cada tres mil casos) sea considerado como una omisión inexcusable, sino que además se trata de contingencia que requiere más de un examen para evitarla (los exámenes endoscópicos y radiológicos son, por separado, insuficientes para una adecuada detección de la fístula). Podría decirse que el criterio de los jueces ha sido muy draconiano en este caso, y si se lleva adelante una investigación a fondo sobre las repercusiones de este criterio en otras decisiones judiciales sobre la materia (aportaría mucho alguien que se proponga llevar adelante esta tarea de investigación en nuestra jurisprudencia), no cabe duda de que los críticos del privilegio se encontrarían contra las cuerdas si tal investigación revelara que los criterios de evaluación de la culpa de los médicos no resultan razonables por su "dureza". Si esto fuese así, el privilegio a favor de los médicos se fundamentaría en la preocupación ya señalada: evitar que estos profesionales asuman responsabilidades de manera injusta. La realidad judicial podría desmentir a la doctrina que pregona la desaparición del privilegio, al menos en el ámbito de la medicina.

\section{Una cuestión en la penumbra: ¿el artículo 36 de la Ley General de Salud impide la aplicación del artículo 1762 del Código Civil en las actividades médicas?}

Al margen de la existencia de un importante margen de complejidad en la problemática del fundamento del privilegio consagrado en el artículo 1762 del Código Civil, noto que nuestra doctrina no ha contrastado esta norma con el artículo 36 de la Ley General de Salud, como tampoco lo ha hecho nuestra jurisprudencia. Este artículo señala: Los profesionales, técnicos y auxiliares a que se refiere este Capítulo, son responsables por los daños y perjuicios que ocasionen al paciente por el ejercicio negligente, imprudente e imperito de sus actividades.

Tiene que advertirse, de inmediato, que según esta norma especial ya no es indispensable la culpa inexcusable o el dolo para que el médico asuma responsabilidad, bastando la sola falta de diligencia, esto es la culpa leve. Si se tiene en cuenta que el artículo 1762 del Código Civil se aplica a las actividades profesionales en general y el artículo 36 de la Ley General de Salud a las actividades médicas en particular, puede sostener que, en base al principio de especialidad, el privilegio ya no se aplica en el campo de la responsabilidad civil médica. Cabe insistir, conforme a esta última norma, el dolo y la culpa grave ya no son presupuestos indispensables para que el profesional de la medicina asuma responsabilidad. A mayor abundamiento, el criterio de la lex posterior también podría aplicarse, ya que la ley especial en mención es posterior al Código Civil.

Es verdad, sin embargo, que la doctrina nacional posterior a la vigencia de la Ley General de Salud, no menciona que el privilegio haya sido afectado en el ámbito de la responsabilidad civil médica. Mucho menos puede esperarse que la jurisprudencia haya notado esta antinomia normativa. De hecho, un sector reputado de nuestra doctrina ha 
sostenido que nuestra judicatura prescinde indebidamente del principio de especialidad, desaplicando la Ley General de Salud en muchos supuestos ${ }^{115}$. Es importante resaltar que la incompatibilidad entre los citados artículos 36 y 1762 se puede presentar sin que importe qué interpretación se adopte con respecto a este último artículo. Efectivamente, si se entiende que el privilegio aplica solamente en los asuntos profesionales especialmente dificultosos, pues este mismo supuesto puede perfectamente considerarse "englobado" en la normativa especial, ya que ésta no hace distingo alguno. Más todavía si se considera que el privilegio se refiere a todo asunto profesional: la normativa especial justamente regula toda actividad de un profesional médico.

Plantear la idea de que el privilegio-en sede de responsabilidad civil médica- se mantiene inconmovible frente a la Ley General de Salud, sería ciertamente propio de los defensores del artículo 1762 del Código Civil. Podría señalarse, en tal orden de ideas, que la normativa especial es aplicable sólo en materia aquiliana o extracontractual, haciéndose una interpretación restrictiva del artículo 36 de la Ley General de Salud, dejando a salvo el rol de la norma del Código Civil en el ámbito contractual o por inejecución de obligaciones. No obstante, llama poderosamente la atención que los críticos del privilegio no hayan explotado el contenido del artículo 36 mentado, a fin de considerar suprimido por completo el privilegio en el ámbito de la responsabilidad médica.

Otro aspecto merece ser resaltado: lo cierto es que, guste o no, los defensores del privilegio pueden adoptar una interpretación restrictiva de la normativa especial. Si se entiende que el privilegio es necesario, y ya vimos que pueden existir razones no fáciles de criticar para sustentar tal idea, pues habría que decir que no estaríamos ante una auténtica antinomia, ya que la misma puede eliminarse mediante una interpretación ${ }^{116}$ que se entendería como acorde con las necesidades sociales (necesidad de innovación en las actividades científicas y/o necesidad de neutralizar criterios judiciales de valoración de culpa que incorrectamente atribuyen responsabilidad a los profesionales de la salud). Volveríamos, pues, al debate anterior.

\section{Desaplicando el artículo 1762 del Código Civil: el caso del artículo 3.5 de la Ley de las Personas Adultas Mayores}

Replantearse el camino es necesario en un escenario como este. No hay duda de que el artículo 36 de la Ley General de Salud poco o nada ha afectado al privilegio tantas veces mencionado. Pero, como se advirtió, incluso generando un debate en torno a la presunta antinomia ya descrita, poco podría lograrse, ya que tanto críticos como defensores podrían mantener incólumes sus posturas. Empero, creo que la Ley de Personas Adultas Mayores Ley 28803 sí tiene una norma que puede complicar mucho el escenario normativo para quienes defienden el privilegio en el campo de la responsabilidad médica. En efecto, el artículo 3.5 de esta ley señala que las personas adultas mayores tienen un acceso a la atención preferente en los servicios de salud integral.

Frente a un privilegio que podríamos considerar de carácter general, se alza un privilegio de tipo especial, por lo que deberíamos preferir a éste último: el artículo 1762 del Código Civil expresa una preferencia por el interés de los profesionales en el ámbito de sus actividades, empero el artículo 3.5 de la Ley de Personas adultas mayores expresa una

\footnotetext{
115 Ibid. pp. 736 y 737.

${ }^{116}$ Chiassoni Pierluigi, Técnicas de interpretación jurídica. Traducción de Pau Luque Sánchez y Maribel Narváez Mora. Madrid: Marcial Pons, 2011, pp. 310 y ss.
} 
preferencia por el interés de los ancianos en el ámbito de los servicios médicos. La incompatibilidad salta a la vista. Resulta harto difícil sostener que el profesional médico mantiene su privilegio incólume cuando tiene a una persona adulta mayor como paciente y, al mismo tiempo, señalar que esta persona es objeto de un trato preferencial al recibir atención médica ¿De qué preferencia puede hablarse si el profesional de la salud ostenta el "derecho" 117 de omitir la diligencia ordinaria al tratar a la persona adulta mayor, tal como lo puede hacer con cualquier otro paciente?

A pesar de que podamos compartir la idea de que el privilegio para los profesionales de la salud es oportuno, considero que el artículo 3.5 de la Ley de Personas Adultas Mayores hace que tal privilegio no se aplique cuando el paciente es un adulto mayor. Habría que forzar el texto de esta normativa especial para tratar de mantener incólume el privilegio establecido por el Código Civil. No tengo duda de que los críticos de la normativa me darían la razón, y patrocinarían la idea de aplicar el principio de especialidad para considerar inaplicable el privilegio del artículo 1762 del Código Civil, de tal suerte que la atención preferencial en materia de salud haría que los médicos tengan el genuino deber de emplear la diligencia ordinaria cuando tratan a un adulto mayor, en caso incumplan este deber asumirán el deber de indemnizar correspondiente. Así también, se podría agregar que el artículo 1762 del Código Civil, en rigor, no contiene ningún derecho a omitir la diligencia ordinaria, sino un régimen excepcional de responsabilidad civil, mientras que el artículo 3.5 sí contiene un auténtico derecho subjetivo: el de exigir una atención médica preferencial. Los críticos del privilegio podrían argumentar, además, que el mantenimiento del privilegio implicaría entender que la norma civil restringe el derecho consagrado por la norma especial, lo cual no tiene en cuenta que frente a cada circunstancia de restricción de derechos, es procedente averiguar la razonabilidad y proporcionalidad de tal restricción, actuando siempre a favor del derecho y no en contra de él cuando haya duda, o aplicabilidad poco clara de la norma restrictiva ${ }^{118}$. En el análisis, entonces, hay que preferir el derecho del adulto mayor, en lugar de la aplicación de un régimen excepcional de responsabilidad civil: no resulta razonable que el privilegio se mantenga, ya que ello prácticamente haría inútil el derecho a la atención médica preferencial que establece la ley especial a favor de los adultos mayores.

Visualizar el asunto con otra perspectiva, empero, no es imposible: podría aseverarse que el artículo 3.5 de La Ley de las Personas Adultas Mayores se refiere simplemente a que los ancianos deben ser atendidos antes que otros pacientes, ante la eventual insuficiencia de recursos humanos y logísticos, de tal suerte que esta norma especial no puede afectar el privilegio que los profesionales médicos ostentan. Pero una interpretación como esta tiene un inconveniente no poco serio: implicaría aceptar que la Ley de las Personas Adultas Mayores no hace más que repetir lo ya establecido en el artículo 1 de la Ley que establece la atención preferente a las mujeres embarazadas, las niñas, niños, los adultos mayores, en lugares de atención al público - Ley $\mathrm{N}^{\circ}$ 27408. Recuérdese lo que indicaba un crítico del privilegio, pero defendiendo su amplia aplicación en el campo operativo: es mala técnica legislativa usar sinónimos y reiteraciones porque no aclaran sino que confunden. Y como debemos suponer que los códigos están bien hechos y que no están mal hechos, tenemos que concluir

117 Aquí no empleo el término "derecho", como es obvio, en un sentido técnico. Si el profesional tuviese semejante derecho, pues se tendría que concluir que puede omitir la diligencia ordinaria deliberadamente, lo cual constituiría un claro supuesto de dolo, el cual sí es fuente de responsabilidad conforme al propio artículo 1762 del Código Civil.

${ }^{118}$ Rubio Correa, Marcial, Aplicación analógica de la ley. En: AAVV. Código Civil Comentado. T. I. Lima: Gaceta Jurídica, 2007, p. 37. 
que se trata de dos hipótesis distintas ${ }^{119}$. En este caso, no se puede presumir que las leyes estén mal hechas, de manera que el artículo 3.5 de la Ley de Personas Adultas Mayores no debe entenderse como una mera reproducción parcial del artículo 1 de la Ley 27408. Esto implicaría auspiciar una interpretación que confiere un significado redundante a la normativa contemplada en la Ley de Personas Adultas Mayores. Se impone la necesidad de atribuir al artículo 3.5 de la Ley de Personas Adultas Mayores un significado diverso al del artículo 1 de la Ley 27408. En lo posible, deben rechazarse aquellas interpretaciones que atribuyan al artículo 3.5 la calidad de enunciado normativo superfluo ${ }^{120}$. Creo que no está demás reiterar una idea ya sugerida: se puede aceptar o incluso defender la idea de mantener el privilegio en el ámbito de la responsabilidad civil médica, pero considero que la redacción de esta normativa especial hace difícil sostener tal privilegio cuando el paciente es una persona adulta mayor. Para concluir este punto, me permito recordar la ya citada disyuntiva que se planteaba uno de los autorizados defensores del privilegio: Comprendo la dificultad de optar entre la posición de exigir al prestador de servicios la observancia de la diligencia ordinaria y la de propiciar el avance de la ciencia y de la técnica, aun a costa de una irresponsabilidad del deudor, pero en la necesidad de hacerlo opto por la segunda posición ${ }^{121}$. Ante esto, hay que decir que en el artículo 3.5 de la Ley de Personas Adultas Mayores, el legislador-guste o no- habría optado por la primera posición.

\section{Otras posibilidades de inaplicación}

Obsérvese, entonces, que es viable plantear nuevos enfoques normativos en el -ya antiguo entre nosotros- debate sobre el privilegio de los profesionales en el ámbito de la responsabilidad civil. Pero no se crea que sólo el caso de los adultos mayores pueda implicar una desaplicación del privilegio en cuestión. De hecho, el caso de los concebidos, niños, niñas y adolescentes también pueden ser analizados como supuestos de no aplicación del privilegio. El caso de los concebidos resulta particularmente relevante, ya que se trata de un sujeto de derecho privilegiado tal como indica el inciso 1 del artículo 2 de la Constitución Política del Estado y artículo 1 del Código Civil. Al respecto, cabe mencionar que (...) el concebido es un sujeto de derecho, al cual no se le atribuyen solamente derechos, sino que se le imputan, correlativamente, deberes. Un derecho no se encuentra aislado, siempre tendrá una contrapartida que será un deber. El concepto de "efectos favorables" ("para todo cuanto le favorece" como expresa el Código Civil peruano) debe ser entendido, de tal manera que, frente a los derechos y deberes que han de contraer, sean más predominantes los resultados que beneficien, que sean positivos para el concebido, en vez de aquellos que han de ser negativos ${ }^{122}$. Por lo tanto, si el paciente es un concebido, no parece que el mantenimiento del privilegio a favor del médico sea acorde con la condición de sujeto privilegiado que aquél ostenta, lo cual resultaría contrario no sólo al Código Civil, sino también a la Constitución. Otro tanto puede señalarse en relación a los niños, niñas y adolescentes, que ostentan el llamado interés superior, mismo que se encuentra consagradoentre otros dispositivos, incluso de carácter internacional suscritos por nuestro país-en el artículo IX del Título Preliminar del Código de los Niños y Adolescentes. Este interés superior debe necesariamente ser tenido en cuenta al momento de analizar si se mantiene el privilegio del profesional (médico o no) que presta un servicio determinado a un niño, niña o adolescente.

\footnotetext{
${ }^{119}$ De TraZeGniES GRANDA., Fernando, Op. cit. p. 388.

${ }^{120}$ TARELlo. Giovanni, L'interpretazione della legge. Milán: Giuffrè, 1980, p. 371.

${ }^{121}$ De la Puente Y Lavalle., Manuel Op. cit. p. 38.

${ }^{122}$ Juan EsPINOZA EsPINOZA. Derecho de las personas. T. I. Lima: Grijley - Iustitia, 2012, p. 51.
} 
Rechazar o defender el privilegio que ostentan los profesionales no es suficiente. Hay un marco normativo importante con el cual las críticas o defensas del privilegio deben saldar cuentas. Y tal marco, como se ha visto, no sólo se limita al Código Civil, sino que involucra también a la legislación especial, la cual parece no haber sido tomada en cuenta de forma apropiada. Además, la experiencia jurisprudencial resulta decisiva para adoptar posiciones en torno a la idoneidad del privilegio. No es poco lo que ha quedado en el tintero, pero confío en que no está lejana la ocasión en que pueda compartir con usted, amable lector, mayores análisis críticos sobre este interesante tema. Por ahora, sólo espero haber alcanzado el modesto objetivo trazado al inicio de estas líneas. 


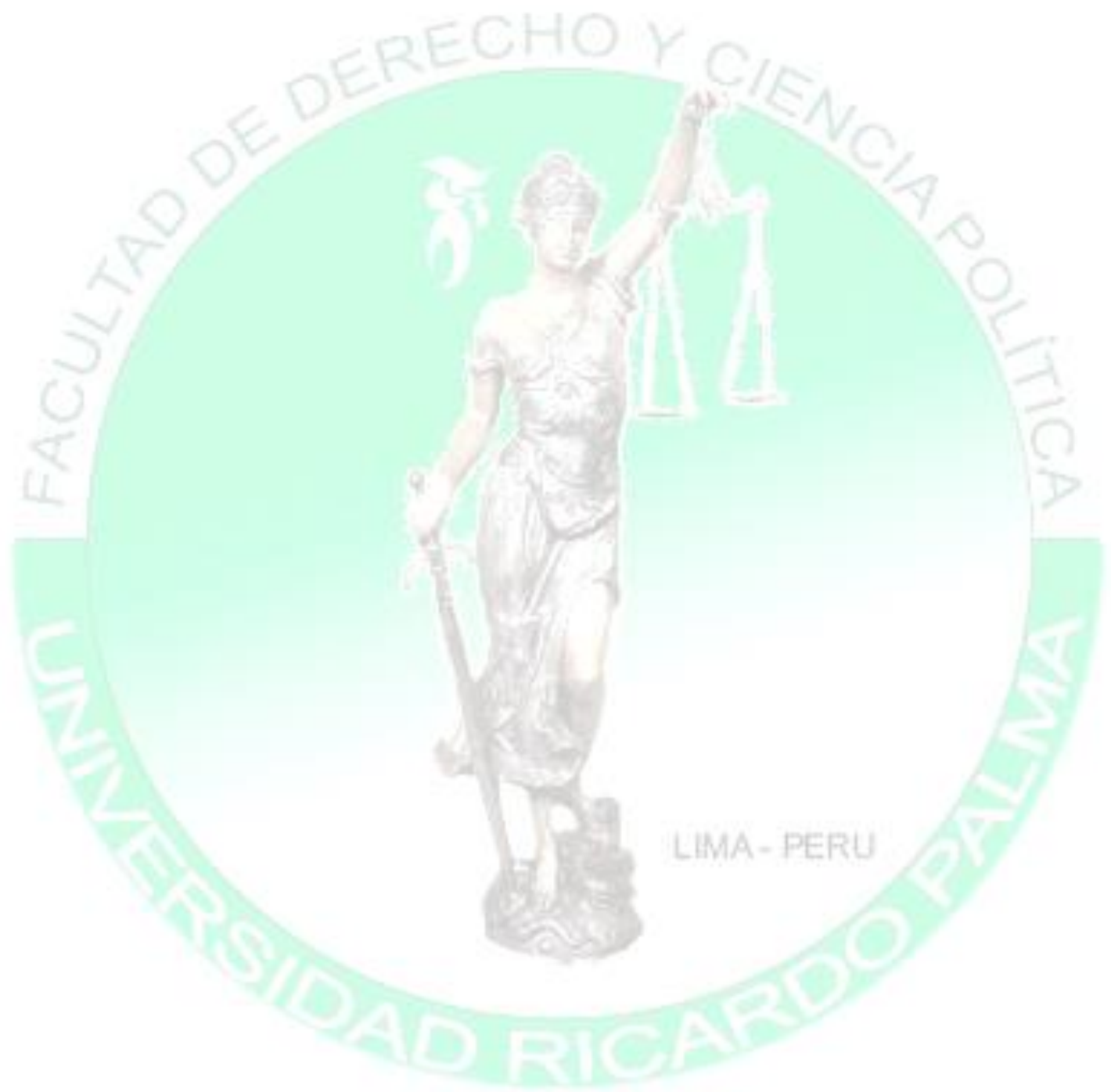

